\title{
Fluid Flow in A Four-strand Bloom Continuous Casting Tundish with Different Flow Modifiers
}

\author{
Liangcai ZHONG, ${ }^{1)}$ Baokuang $\mathrm{LI}^{11}$ Yingxiong $\mathrm{ZHU},{ }^{1)}$ Rengui WANG, ${ }^{2)}$ Wenzhong WANG ${ }^{2)}$ and \\ Xiaojun ZHANG ${ }^{21}$
}

1) School of Materials and Metallurgy, Northeastern University, No. 11, Lane 3, Wenhua Road, Heping District, Shenyang, 110004, Liaoning, China. $\quad$ 1) Anshan Iron and Steel Co., Wuyi Road, Anshan, 114021, Liaoning, China.

(Received on June 22, 2006; accepted on September 11, 2006)

\begin{abstract}
Fluid flows in a four-strand tundish for bloom continuous casting have been investigated with physical modeling and mathematical simulation methods. The liquid steel flow velocity fields in the former tundish and the optimal one with a turbulence inhibitor and newly-designed baffles were numerically calculated and the flow characteristics in the two cases and other tundish configurations were measured in the physical modeling. The results in the physical modeling experiments showed that large difference in the Residence Time Distribution (RTD) curves of two outlets in one side of the former configuration tundish existed. It was found from the numerical calculation of the velocity fields in the tundishes that with the former tundish configuration velocities and turbulent degree of the liquid steel flow in the impact zone of the tundish were large due to the high velocities of liquid steel from the long shroud of the ladle, which caused in lining corrosion and slag entrapment due to the surface eddies. Asymmetric velocity field in the tundish with the former baffles formed and short circuit flow existed in one side of the four-strand tundish. For the optimal configuration of the tundish with a turbulence inhibitor and newly-designed baffles, very similar RTD curves of the two outlets in the same side of the tundish were achieved. The velocities and turbulent degree in the impacting zone of the tundish were depressed and quiet and symmetric molten steel flow was obtained. Eddies on surface and short circuit flow in the optimal tundish disappeared. Such improvement of liquid steel flow in the tundish would increase the ability of inclusion removal. Turbulence inhibitors should be used with other well-designed flow control devices for effective improvement to fluid flow characteristics in tundishes.
\end{abstract}

KEY WORDS: bloom continuous casting; four-strand tundish; liquid steel flow; mathematical simulation; flow characteristic; physical modeling; flow control device.

\section{Introduction}

Tundishes in continuous casting are important intermediate buffers between ladles and moulds. It is well known that liquid steel flow characteristics in tundishes have a large influence on the cleanness of steel. ${ }^{1}$ In order to obtain ideal fluid flow characteristics in tundishes, flow control devices, such as, weirs, dams, baffles with inclined holes and turbulence inhibitors, have been widely used in continuous casting tundishes. All of them are designed to increase residence times and plug flow volume of liquid steel in tundishes for enhancing inclusion removal from the molten steel. Usually, two research methods, physical modeling and mathematical simulation, are employed to optimize tundish configurations. ${ }^{2-8)}$ Lowry and Sahai ${ }^{9}$ studied the steel flow in a "T"-shaped six strand tundish with different configurations with a mathematical model study, a water model study and a tracer study. They found the mathematical and water modeling results could be confidently applied to actual tundish systems. The changes in flow represented by the Residence Time Distribution (RTD) were similar in all three of the flow systems. The multiple-hole baffles in- stalled in the "T"-shape tundish produced a $35 \%$ increase in mean residence time for the steel to the inside nozzle accompanied by a slight decrease in residence time to the outside nozzle. The multiple-hole baffle produced a more uniform distribution of liquid steel to different nozzles in the tundish studied. Morales et al. ${ }^{10)}$ investigated the influence of a turbulence inhibitor and different baffles on steel cleanness in a four-strand bloom continuous casting tundish with water modeling. Their results showed that the optimal tundish configuration could obtain very similar RTD curves for the both strands in the same side and product rejection, during actual industrial trials, due to steel cleanness decreased from an average of 3 to $0 \%$ after the optimization. Madias et al. ${ }^{11)}$ carried out a research on fluid flow in a six strand tundish with an advanced pouring box replacing the former baffles and flat impact pad in water model tests. Their research illustrated that turbulence in the tundish center during transients and slag emulsification were decreased. Minimum and average residence time and plug flow volume were increased. Sahay et al. ${ }^{12)}$ used asymmetry baffles with holes in the half of the baffles to improve strand performance in tundish of six strand billet caster. 
Significant improvements in flow profile were achieved in their research. Residence time distribution uniformity between nozzles improved and the temperature difference between inner and outer nozzles was less than $3^{\circ} \mathrm{C}$. Kim et al. ${ }^{13)}$ conducted experiments in a full-scale physical model of a delta-shaped, four-strand tundish to investigate the effect of flow modifiers on tundish flow performance by using tow different types of flow control devices, an existing Impact pad and a "Turbo-Stop". They found that the impact pad gave longer average residence times and smaller residence time differences between the inner and outer nozzles, although the Turbo-Stop appeared to decrease the turbulence intensity levels more than the Impact pad. While the Impact pad resulted in a lower residual percentage of inclusions than did the Turbo-Stop during steady state operations, the Turbo-Stop performed better during transit operating conditions associated with ladle changes and tundish filling.

In the present work fluid flow in a $30 \mathrm{t}$ four-strand tundish with different flow control devices was investigated by using physical modeling and mathematical simulation methods. In the physical modeling experiments, RTD curves of fluid flow in the tundish with different configurations were measured and flow characteristics were determined from the RTD curves. In the mathematical simulation, governing equations for the molten steel flow in the tundish with different flow control modifiers were set up and then numerically calculated to obtain liquid steel velocity distributions.

\section{Tundish Configurations}

The former tundish configuration is shown in Fig. 1(a). Two baffles were used in the former tundish configuration and each baffle had three holes which upwardly inclined to the horizontal by $30^{\circ}$, as shown in Fig. 2(a). The two baffles were not asymmetric in terms of hole positions. Lower positions of the holes in the left baffle were chosen to be for the casting start at the left side of the tundish prior to the right side. During the casting start, molten steel first flowed into the left side of the tundish through the hole with the lowest position. When the liquid steel level reached the casting start height at the left side of the tundish, strand 1 and 2 started to cast prior to strand 3 and 4 . As the steel level in the tundish impact zone rose up to the lowest hole location in the right baffle, molten steel flowed into the
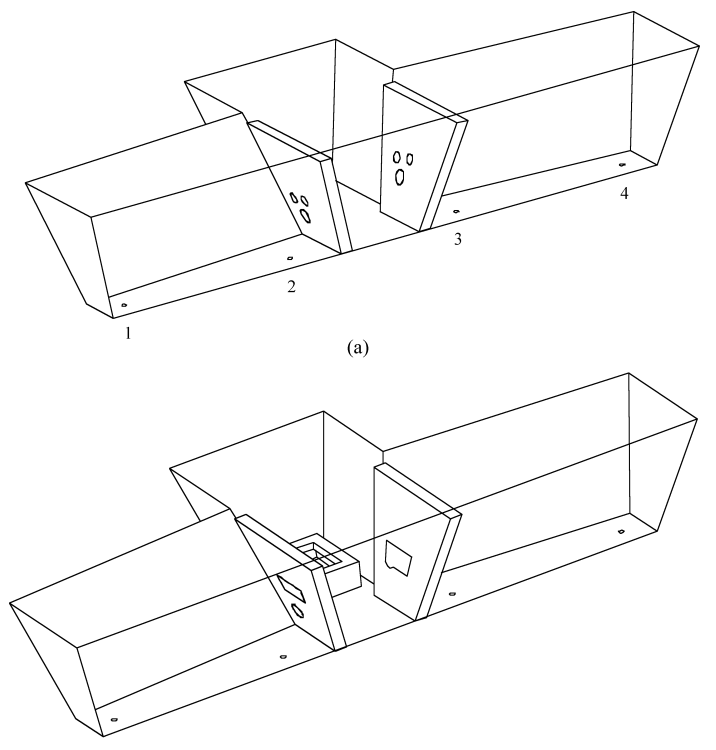

(b)

Fig. 1. Tundish configurations before (a) and after (b) the optimization.

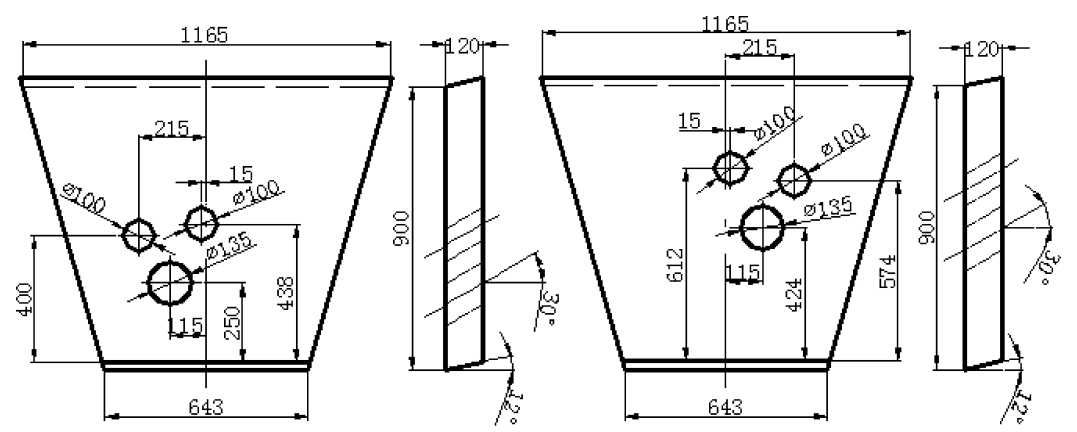

(a) Two former baffles
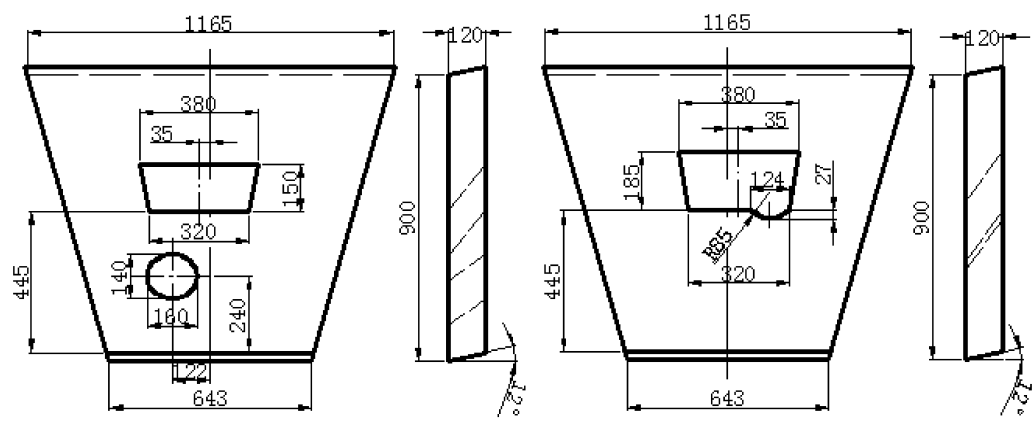

(b) Two newly-designed baffles

Fig. 2. Baffles used in the former tundish configuration (a) and in the optimal one (b). 
right side of the tundish. After the level of liquid steel at this side arrived at the casting start height, strand 3 and 4 then started to cast. Last, the molten steel level in the tundish ascended to the normal casting height and the steady state casting began.

It was known from the physical modeling experiments for the former tundish configuration that large difference in the fluid flow characteristics, such as, minimum residence time, concentration peak time and mean residence time, between the two outlets at the same side of the tundish existed, as shown in Sec. 4. In industrial production, the baffles were easily broken due to the small distances between every two holes after several heats were cast and lost the control effect to the molten steel flow. In order to improve the fluid flow performance in the tundish, decrease the difference in the flow characteristics and prolong the life time of the baffles, two newly-designed baffles and a turbulence inhibitor were employed in the tundish, as shown in Fig. 1(b) and Fig. 2(b). In order to keep the same casting start sequence as before, that is, strand 1 and 2 started to cast prior to strand 3 and 4, a small elliptical hole in the left side baffle of the tundish was opened at the same position as the lowest hole in the former left baffle. Under the steady state of casting after the casting start, molten steel flowed downstream through the elliptical hole and the large trapeziform hole in the left baffle, but mainly through the trapeziform hole due to its large cross section. A groove with an arc section was design at the right corner (see Fig. 2(b)) on the bottom of the trapeziform hole in the right baffle to avoid the direct impact of liquid steel to the outlet of strand 3 during the casting start. The height of the trapeziform hole in the right baffle was devised higher than that in the left one to let the tow baffles have almost the same flow section area at each side of the tundish.

Molten steel flow behaviors under steady state in the two configurations of tundish (Figs. 1(a) and 1(b)) with the asymmetric baffles (Figs. 2(a) and 2(b)) were investigated with a mathematical model, respectively. Flow characteristics in these two cases and other tundish configurations with only the turbulence inhibitor, only the new-designed baffles or the turbulence inhibitor and two former baffles were also measured in the physical modeling experiments.

\section{Mathematical and Physical Models}

\subsection{Mathematical Model}

The liquid steel flow in the continuous casting tundish can be considered to be three-dimensional, turbulent. The flow is treated as steady by neglecting the phenomena involved during filling and emptying of the tundish. The effect of surface slag to the flow is ignored and the melt surface is assumed to be flat. The molten steel is Newtonian and incompressible fluid. Therefore, the governing equations in Cartesian tensional form for the liquid steel flow in the tundish can be written as:

Continuity:

$$
\frac{\partial}{\partial x_{i}}\left(\rho u_{i}\right)=0
$$

Momentum:

$$
\frac{\partial}{\partial x_{i}}\left(\rho u_{i} u_{j}\right)=-\frac{\partial P}{\partial x_{i}}+\frac{\partial}{\partial x_{i}}\left[\mu_{\mathrm{eff}}\left(\frac{\partial u_{i}}{\partial x_{j}}+\frac{\partial u_{j}}{\partial x_{i}}\right)\right]+\rho g_{i}
$$

where $\rho$ is the density of liquid steel, equal to $7020 \mathrm{~kg} / \mathrm{m}^{3}$ here; $u$ is the velocity; $P$ is the pressure; $g$ is gravitation acceleration; $\mu_{\text {eff }}$ is effective viscosity. $i$ and $j$ represent the three coordinate directions. $\mu_{\text {eff }}$ is equal to the sum of molecular and turbulent viscosity of steel. Here, the molecular viscosity of liquid steel is equal to $0.0059 \mathrm{~Pa} \cdot \mathrm{s}$. The turbulent viscosity is calculated through its relationship with the kinetic energy and its dissipation rate by the $k-\varepsilon$ model. ${ }^{14)}$ The turbulent kinetic energy, $k$ and its dissipation rate, $\varepsilon$ can be expressed with the following equations:

Turbulent kinetic energy:

$$
\frac{\partial}{\partial x_{i}}\left(\rho u_{i} k\right)=\frac{\partial}{\partial x_{i}}\left(\frac{\mu_{\mathrm{eff}}}{o_{k}} \frac{\partial k}{\partial x_{i}}\right)+G-\rho \varepsilon
$$

Dissipation rate of turbulent kinetic energy:

$$
\frac{\partial}{\partial x_{i}}\left(\rho u_{i} \varepsilon\right)=\frac{\partial}{\partial x_{i}}\left(\frac{\mu_{\mathrm{eff}}}{o_{\varepsilon}} \frac{\partial \varepsilon}{\partial x_{i}}\right)+\frac{\varepsilon}{k}\left(C_{1} G-C_{2} \rho \varepsilon\right) \ldots
$$

The generation term, $G$ in Eqs. (3) and (4) can be given as:

$$
G=2 \mu_{\mathrm{t}}\left(\frac{\partial u_{i}}{\partial x_{i}}\right)^{2}+\mu_{\mathrm{t}}\left(\frac{\partial u_{i}}{\partial x_{j}}+\frac{\partial u_{j}}{\partial x_{i}}\right)^{2}
$$

The turbulent viscosity, $\mu_{\mathrm{t}}$ can be written as:

$$
\mu_{\mathrm{t}}=\frac{C_{\mu} \rho k^{2}}{\varepsilon}
$$

$C_{1}, C_{2}, C_{\mu}, \sigma_{k}$ and $\sigma_{\varepsilon}$ are the empirical constants of the $k-\varepsilon$ model and were assigned to their standard values ${ }^{14)}: 1.44$, $1.92,0.09,1.0$ and 1.30 , respectively.

The whole volume filled with molten steel in the tundish was chosen as the numerical calculation domain. The above continuity, momentum equations were solved with the equations for $k$ and $\varepsilon$ by using the following boundary conditions. Non-slipping conditions were applied as boundary conditions to all solid walls. Frictionless conditions were used to the free surface of liquid steel. The logarithmic law was employed to all nodes closest to any solid walls. The vertical velocity profiles of the liquid steel at the inlet as well as at the outlet nozzles of the tundish were assumed to be uniform through the cross sections and the other two velocity components were assumed to be zero. The values of $k$ and $\varepsilon$ at the inlet were calculated from the inlet average velocity through the well known equations. A constant mass flow rate of steel from the ladle to the tundish was $2.98 \mathrm{ton} / \mathrm{min}$ for the mathematical simulation.

A finite difference technique was used to solve the governing equations numerically. Discretization equations were derived from the governing equations and were solved by using an implicit finite difference procedure called SIMPLE algorithmic. The calculation domain was divided into a $212 \times 102 \times 36$ grid network. A criterion for convergence was set to be less than $10^{-5}$ on all variables and computa- 
tions were carried out until the relative sum of residuals on all variables all fell bellow the stipulated value.

\subsection{Physical Model}

In order to insure the fluid flowing between the model tundish and prototype tundish for isothermal and non-reactive systems similar, geometrical and dynamic similarities must be satisfied between the two vessels. In the present work, the ratio of geometrical similarity of model tundish to the prototype was chosen to be $1: 2.5$. Dynamic similarity required to respect simultaneous equality of both turbulent Reynolds and Froude numbers, but it was impossible to keep the condition satisfied in reduced scale modeling studies. The computational work of Sahai and Burval ${ }^{15)}$ and the experimental work of Singh and Koria ${ }^{16)}$ showed that the magnitude of turbulent Reynolds number under turbulent flow range in different tundishes was very similar. Therefore, Froude number between the model tundish and the prototype one was maintained to be equivalent in this work.

A schematic of the experimental apparatus is shown in Fig. 3. A RTD curve of the fluid flowing in the tundish can be obtained by stimulus-response technique to investigate the effect of different tundish configuration on the fluid flow characteristics in the tundish. Before measuring, the liquid levels of the ladle and the tundish were raised to the predetermined height. Then tundish nozzles were opened. After attaining steady-state flow condition, $250 \mathrm{~mL}$ of $\mathrm{NaCl}$ saturated solution was used as a tracer and was injected into the water stream flowing through the long shroud. One conductivity probe which was connected to a conductivity meter was installed below one of the outlets of the tundish to measure the instantaneous concentration of the tracer as a function of time. The measurement data were plotted with a recorder and input into a computer to calculate the fluid flow characteristics.

From the RTD curves, minimum residence time, $t_{\min }$,

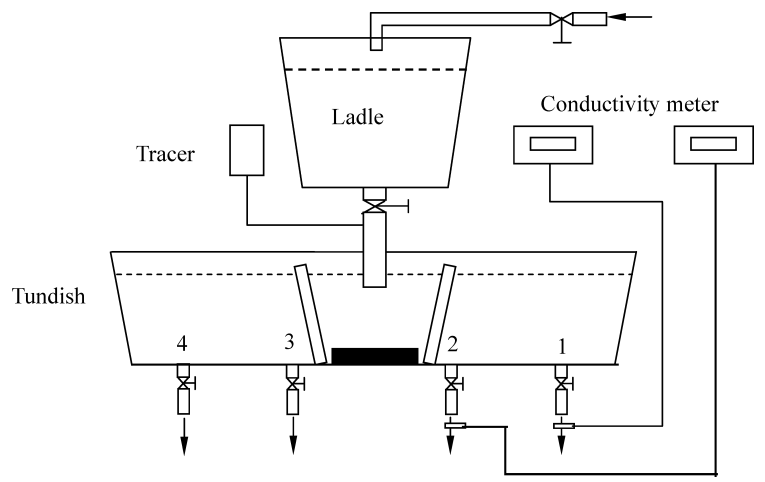

Fig. 3. Schematic of physical experimental apparatus. peak concentration time, $t_{\max }$, and mean residence time, $t_{\mathrm{av}}$, can be obtained for every experiment. Considering that there is fluid exchange between the fluids in the dead zone and in the active zone, the flow model proposed by Sahai and $\mathrm{Emi}^{17)}$ was employed in this work to calculate dead volume fraction, $V_{\mathrm{dv}}$, but the fractions of plug flow and wellmixed volumes were still calculated with the modified mixed model from Ahuja and Sahai. ${ }^{18)}$

\section{Results and Discussion}

\subsection{Physical Modeling}

The RTD curves of strand 1 and 2 measured in the physical experiment for the former tundish configuration is shown in Fig. 4. The flow characteristics in the tundish obtained from the RTD curves are given in Table 1. It is known from Fig. 4 that there are significant differences between the tracer concentrations out of the two outlets as a function of time with the former tundish configuration. These illustrate that large differences in flow characteristics of the two outlets exist, as shown in Table 1. It is known from Table 1 that the minimum residence and peak concentration times are small and the dead volume fractions are large in the former tundish. Tracer reached to strand 1 outlet first due to small section area of holes in the baffles, which caused in shorter minimum residence and peak concentration times in strand 1 than those in strand 2.

The optimal tundish configuration is consisted of a square turbulence inhibitor and two newly-designed baffles, as shown in Fig. 1(b). The RTD curves of strand 1 and 2 for this tundish and the flow characteristics are presented in Fig. 5 and in Table 1, respectively. As illustrated in Fig. 5, the RTD curves of strand 1 and 2 are very similar, which means that the flow characteristics in these two strands are almost the same with each other. It is known from Table 1 that the flow characteristics, such as, minimum residence

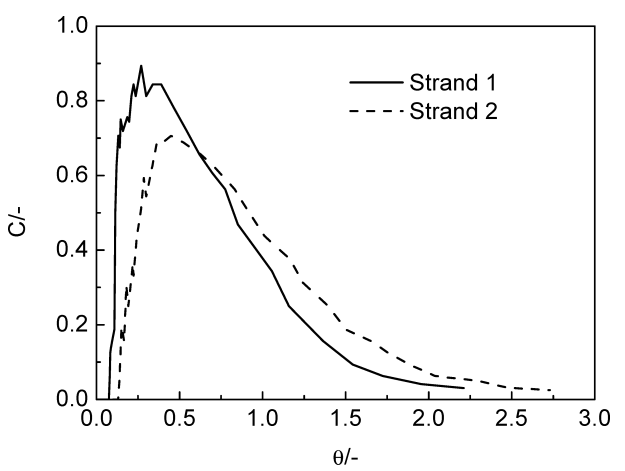

Fig. 4. RTD curves of strand 1 and 2 in the former tundish.

Table 1. Fluid flow characteristics before and after the tundish optimization.

\begin{tabular}{|c|c|c|c|c|c|c|c|}
\hline $\begin{array}{c}\text { Tundish } \\
\text { optimization }\end{array}$ & $\begin{array}{c}\text { Strand } \\
\text { number }\end{array}$ & $\mathrm{t}_{\min } / \mathrm{s}$ & $\mathrm{t}_{\max } / \mathrm{s}$ & $\mathrm{t}_{\mathrm{av}} / \mathrm{s}$ & $\mathrm{V}_{\mathrm{pv}} / \%$ & $\mathrm{~V}_{\mathrm{dv}} / \%$ & $\mathrm{~V}_{\mathrm{mv}} / \%$ \\
\hline \multirow{2}{*}{ Before } & 1 & 31 & 89 & 262 & 15.32 & 32.82 & 51.86 \\
\cline { 2 - 8 } & 2 & 45 & 169 & 356 & 27.44 & 20.46 & 52.10 \\
\hline \multirow{2}{*}{ After } & 1 & 56 & 195 & 315 & 32.12 & 21.38 & 46.50 \\
\cline { 2 - 8 } & 2 & 55 & 195 & 333 & 32.12 & 16.02 & 51.86 \\
\hline
\end{tabular}


and peak concentration times and dead volume fraction, were improved after the tundish optimization.

Table 2 shows the flow characteristics in the tundish with different flow control devices. It can be known from Table 2 that the tracer added into the tundish flowed first out of the strand 2 outlet when turbulence inhibitor was used as the only flow control device in the tundish, which resulted in short minimum residence, peak concentration and real average residence time and large dead volume fraction for the strand. Although large minimum residence time appeared in this case for strand 1 , small peak concentration time and large dead volume fraction existed in the strand and there was large difference in flow characteristics between strand 1 and 2 . When the two newly-designed baffles was used as the only flow control devices in the tundish, the minimum residence and real average residence times became similar and the dead volumes decreased and were similar between strand 1 and 2, although short minimum residence times appeared in this case. For the case where the turbulence inhibitor and the former baffles were applied in the tundish, short minimum residence and peak concentration time and large dead volume fraction were present in strand 1 due to small section area of the three holes in the former baffles and large difference in the flow characteristics also existed between strand 1 and 2 .

The above results indicate that turbulence inhibitors can only control the fluid flows in the impact zone of tundishes. In the area far from the turbulence inhibitors, their effect on flow control becomes weak. Therefore, the flow characteristics can not be improved effectively in the tundish only with a turbulence inhibitor. In multi-strand tundishes, if flow control devices such as baffles with holes are not designed

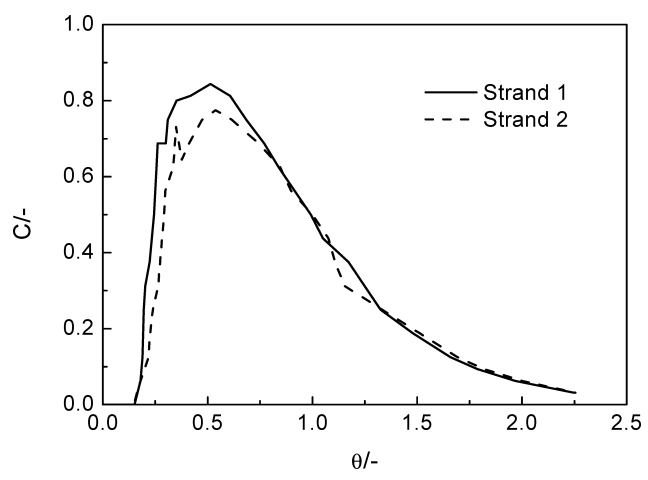

Fig. 5. RTD curves of strand 1 and 2 in the optimal tundish. well, large difference in flow characteristics between strands would be present, which will cause in nonuniformity of residence time and inhomogeneity of temperature in the tundishes. As a result, such fluid flow in the tundishes with unsuitable flow control devices will affect steel quality and castability.

\subsection{Mathematical Simulation}

The velocity field of liquid steel at the symmetric plane in the impact zone of the incoming stream from the ladle shroud for the former tundish is shown in Fig. 6. It is known from the figure that the liquid steel from the shroud impacts the tundish bottom directly with very high velocities. Then it flows fast along the bottom. Such flow would cause serious erosion to the tundish bottom and side wall line in this zone and arise large exogenous inclusions. The flow of liquid steel at the free surface in the tundish is presented in Fig. 7. It is shown in the figure that the surface

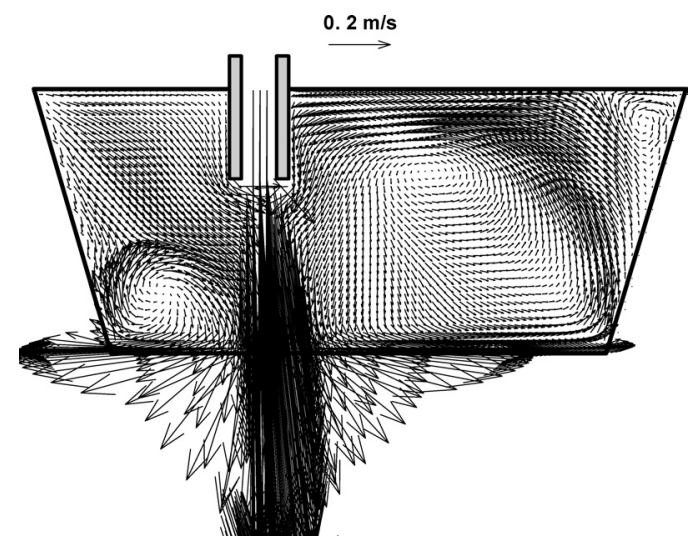

Fig. 6. Velocity distribution at the symmetric plane in the impact zone for the former tundish.

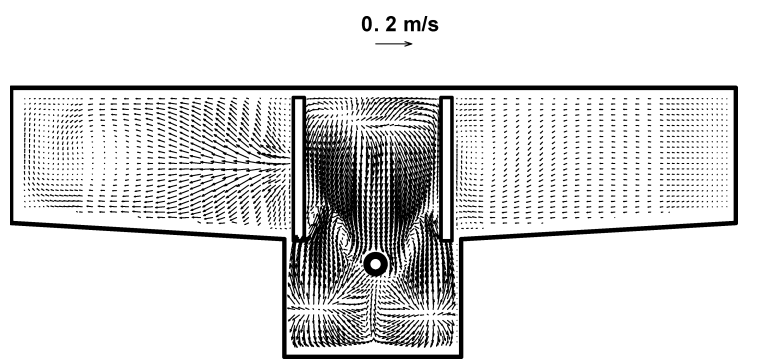

Fig. 7. Flow of liquid steel on the free surface in the former tundish.

Table 2. Fluid flow characteristics in the tundish with different flow control devices.

\begin{tabular}{|c|c|c|c|c|c|c|c|}
\hline $\begin{array}{c}\text { Tundish } \\
\text { configuration }\end{array}$ & $\begin{array}{c}\text { Strand } \\
\text { number }\end{array}$ & $\mathrm{t}_{\min } / \mathrm{s}$ & $\mathrm{t}_{\mathrm{max}} / \mathrm{s}$ & $\mathrm{t}_{\mathrm{av}} / \mathrm{s}$ & $\mathrm{V}_{\mathrm{pv}} / \%$ & $\mathrm{~V}_{\mathrm{dv}} / \%$ & $\mathrm{~V}_{\mathrm{mv}} / \%$ \\
\hline \multirow{2}{*}{$\begin{array}{c}\text { Turbulence } \\
\text { inhibitor }\end{array}$} & 1 & 58 & 72 & 258 & 16.67 & 34.41 & 48.92 \\
\cline { 2 - 8 } & 2 & 17 & 45 & 179 & 7.95 & 53.99 & 38.06 \\
\hline \multirow{2}{*}{$\begin{array}{c}\text { Newly-designed } \\
\text { baffles }\end{array}$} & 1 & 32 & 189 & 315 & 28.33 & 23.32 & 48.35 \\
\cline { 2 - 8 } & 2 & 31 & 98 & 333 & 16.54 & 21.94 & 61.52 \\
\hline \multirow{2}{*}{$\begin{array}{c}\text { TI +former } \\
\text { baffles }\end{array}$} & 2 & 60 & 166 & 342 & 28.97 & 19.74 & 51.29 \\
\cline { 2 - 8 }
\end{tabular}

Note: TI stands for Turbulence Inhibitor. 


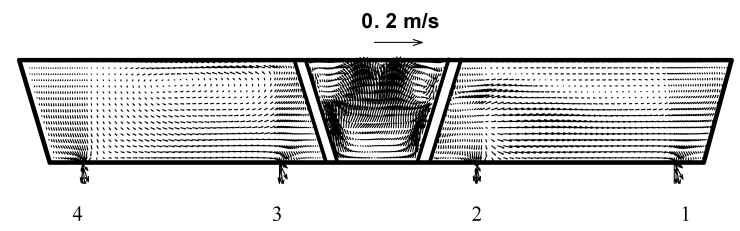

Fig. 8. Molten steel velocity profile at the tundish nozzle plane in the former tundish.

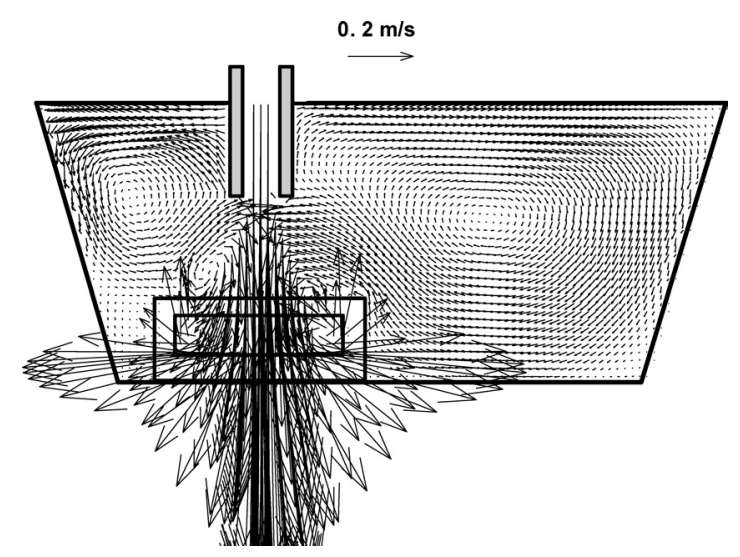

Fig. 9. Liquid steel flow at the symmetric plane at the impact zone in the optimal tundish.

velocities are high and eddies exist near the shroud, which will result in slag entrapment. Asymmetric surface flows can be found at the two sides of the tundish in the figure due to the two asymmetric baffles used (see Fig. 2(a)). At the left side surface in Fig. 7 molten steel flows with higher velocities downstream, while at the right side surface liquid steel flows towards to the right baffle. It is known from Figs. 1(a) and 2(a) that the position of the three holes in the strand 1 and 2 side is lower from the bottom than that of the three holes in the strand 3 and 4 side. Such difference between the tow baffles causes in the asymmetric surface flows at the two sides of the tundish.

Figure 8 illustrates the molten steel velocity profile at the tundish nozzle plane in the former tundish. Asymmetric flows at the two sides of the tundish are also observed in the figure and an obvious short circuit flow at the right side exists, which cause short minimum and average residence times at this side. This affects negatively the performance of this tundish as a reactor.

The liquid steel flow at the symmetric plane in the impact zone of the incoming stream from the ladle to the tundish with a turbulence inhibitor and tow newly designed baffles is illustrated in Fig. 9. It is found from this figure that the momentum of the incoming stream is depressed with the turbulence inhibitor. As a result, the flow velocities at this plane are smaller than those without the flow control device, the erosion of high velocity steel stream to the tundish bottom and side wall line in this zone is prevented and the molten steel flow becomes quiet.

Free surface flow of the liquid steel in the tundish is shown in Fig. 10. Compared with Fig. 7, the free surface flow velocities of the molten steel at the impact zone become smaller, the eddies near the shroud disappear and the free surface flow is smooth, due to the application of the turbulence inhibitor. With the two newly designed baffles, a

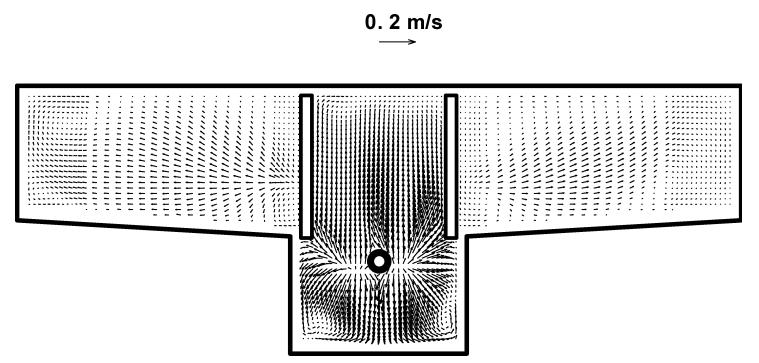

Fig. 10. Free surface flow of the liquid steel in the optimal tundish.

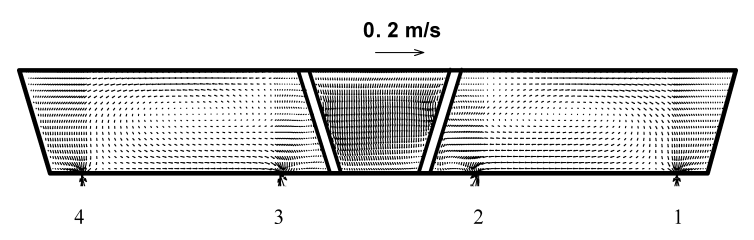

Fig. 11. Velocity field of liquid steel at the tundish nozzle plane in the optimal tundish.

symmetric surface flow at the two sides of the tundish is obtained and the flow velocities at the left side surface are reduced. The velocity field of liquid steel at the tundish nozzle plane is presented in Fig. 11. As shown in this figure, the short circuit flow at the right side in Fig. 7 dose not appear and the flow velocities at this plane become smaller, especially inside the zone between the two baffles.

\section{Conclusions}

There are significant differences in fluid flow performance for the former tundish configuration, which results in large differences in flow characteristics of the two outlets in one side of the tundish. The minimum residence and peak concentration times are small and the dead volume fractions are large in the former tundish.

The RTD curves of the outer and inner outlets in the same side of the tundish are very similar after the tundish optimization with a square turbulence inhibitor and two newly-designed baffles. The flow characteristics in these two strands are almost the same with each other. The flow parameters, such as, minimum residence and peak concentration times and dead volume fractions, are improved after the tundish optimization.

In the former tundish, the liquid steel flow velocities in the impact zone of the incoming stream are high and eddies form easily on the free surface around the long shroud. Asymmetric flows exist at the two sides of the tundish due to the two asymmetric baffles and a short circuit flow at the one side of the tundish is formed.

In the optimized tundish, the velocities and turbulence of molten steel flows are eliminated, symmetric flow at the two sides of the tundish is achieved and short circuit flow and surface eddies in the impact zone are avoided. Such improvements in molten flow characteristics in the tundish would be benefited to the flotation-up for the non-metal inclusions and the decrease in the exogenous inclusions.

Turbulence inhibitors can effectively control and improve the fluid flow in the impact zones of the tundishes, but their effect on flow control becomes weak in the area far from 
the impact zones. Turbulence inhibitors should be used with other well-designed flow control devices such as weirs, dams and baffles for effective improvement to flow characteristics in tundishes.

\section{REFERENCES}

1) D. Mazumdar and R. I. L. Guthrie: ISIJ Int., 39 (1999), 524.

2) R. D. Morales, S. López-Ramírez, J. Palafox-Ramos and D. Zacharias: ISIJ Int., 39 (1999), 455.

3) J. Palafox-Ramos, J. de J. Barreto, S. López-Ramírez and R. D. Morales: Ironmaking Steelmaking, 28 (2001), 101.

4) H.-J. Odenthal, R. Bolling, H. Pfeifer, J.-F. Holzhauser and F.-J. Wahlers: Steel Res., 72 (2001), 466

5) A. Robert and D. Mazumdar: Steel Res., 72 (2001), 97.

6) P. K. Jha, S. K. Dash and S. Kumar: ISIJ Int., 41 (2001), 1437.

7) K. J. Craig, D. J. de Kock, K. W. Makgata and G. J. de Wet: ISIJ Int., 41 (2001), 1194.
8) A. Ramos-Banderas, R. D. Morales, L. García-Demedices and M. Díaz-Cruz: ISIJ Int., 43 (2003), 653.

9) M. L. Lowry and Y. Sahai: Iron Steelmaker, 18 (1991), No. 8, 53.

10) R. D. Morales, J. Palafox-Ramos, S. López-Ramírez, M. A. Domínguez-Crespo, C. Rincón, D. Salazar and A. Dainton: Proc. 81st Steelmaking Conf., ISS, Warrendale, PA, (1998), 325.

11) J. Madias, D. Martin, M. Ferreyra, R. Villoria and A. Garamendy: ISIJ Int., 39 (1999), 787.

12) S. K. Sahay, T. K. De, D. S. Basu and S. Mazundar: Iron Steelmaker, 28 (2001), No. 6, 71.

13) H. B. Kim, R. I. L. Guthrie, M. Isac and R. Thibau: ISS Tech 2003 Int. Tech. Conf. Proc., ISS, Warrendale, PA, (2003), 215.

14) B. E. Launder and D. B. Spalding: Comp. Meth. Appl. Mech. Eng., 3 (1974), 269.

15) Y. Sahai and M. D. Burval: Proc. 50th Electric Furnace Conf., ISS, Warrendale, PA, (1992), 469.

16) S. C. Koria and S. Singh: ISIJ Int., 34 (1994), 784.

17) Y. Sahai and T. Emi: ISIJ Int., 36 (1996), 667.

18) Y. Sahai and R. Ahuja: Ironmaking Steelmaking, 13 (1986), 241. 